\title{
The effectivity of banana leaf-filtered cloth face masks as an alternative protection during the pandemic
}

\author{
Mohamad Saifudin Hakim¹, Mumtihana Muchlis ${ }^{2}$, Fitra Duhita², Rita Dian Pratiwi² \\ ${ }^{1}$ Department of Microbiology, Faculty of Medicine, Public Health and Nursing, Universitas Gadjah Mada, Yogyakarta, Indonesia \\ ${ }^{2}$ Department of Health Information and Services, Vocational College, Universitas Gadjah Mada, Yogyakarta, Indonesia
}

\begin{tabular}{l} 
Article Info \\
\hline Article history: \\
Received Jun 17, 2021 \\
Revised Nov 10, 2021 \\
Accepted Nov 24, 2021 \\
\hline
\end{tabular}

Keywords:

Bacterial filtration efficiency

Banana leaf

Cloth face masks

COVID-19 prevention

Water resistance

\begin{abstract}
The main transmission route of severe acute respiratory syndrome coronavirus 2 (SARS-CoV-2) is through individual droplets of respiratory secretions. Accordingly, the most basic preventive measure is wearing a face mask. Since the issue of medical waste during the pandemic is concerning, developing face masks made of reusable and biodegradable materials is necessary. This study aimed to develop "do-it-yourself" face masks and test the effectiveness of banana leaf-filtered cloth face masks. The design development was conducted by a series of trials for making a mask pattern that can be applied to the cloth. Then, we performed bacterial filtration efficiency (BFE) and water resistance tests to investigate the effectiveness of banana leaf-filtered cloth-based face masks. The dimensions of the developed face mask are $20 \times 18 \mathrm{~cm}$, with a semi-duckbill model, consisting of three layers of washable cotton cloth and a pocket designed for the banana leaf filter. Among 34 leaf-filtered face masks, $61.8 \%$ showed water resistance abilities. Based on the BFE test, the leaf-filtered face masks contained significantly fewer bacteria (the average of $0.417 \times 10^{3} \mathrm{cfu} / \mathrm{cm}^{2}$ ) compared to the cloth face masks without additional leaf filter $\left(30 \times 10^{3} \mathrm{cfu} / \mathrm{cm}^{2}\right)$. Thus, banana leaf-filtered cloth face masks could be considered as alternative protection during the pandemic.
\end{abstract}

This is an open access article under the CC BY-SA license.

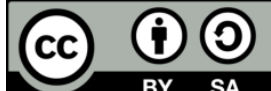

\section{Corresponding Author:}

Mohamad Saifudin Hakim

Department of Microbiology, Faculty of Medicine, Public Health and Nursing, Universitas Gadjah Mada

J1. Farmako, Sekip Utara, Yogyakarta, 55281, Indonesia

Email: m.s.hakim@ugm.ac.id

\section{INTRODUCTION}

Coronavirus disease 2019 (COVID-19), caused by severe acute respiratory syndrome coronavirus 2 (SARS-CoV-2), has spread worldwide. The world health organization (WHO) declared it as a pandemic on March 11, 2020. The most common form of transmission of SARS-CoV-2 is through droplets of respiratory secretions as a person coughs, sneezes, and talks. The characteristics of the droplet particles are $>5$ um in size, remaining in the air over a long period, and passing a certain distance (1.5-2 meters). The droplets containing the viruses adhere to the susceptible mucosal surfaces such as the mouth, eyes, and nose [1]. One of the most important protection measures to prevent disease transmission is by wearing a face mask covering the nose and mouth, especially when coughing or sneezing [2].

The face mask recommended by the WHO [2], [3], is the surgical mask consisting of three layers because it provides the most effective protection against microbes and particle spread. Since the virus transmission has been continuously increasing during the COVID-19 pandemic, everyone traveling outside is required to wear a face mask [2], [3]. Van der Sande et al. [4] stated that any type of face mask could reduce the virus exposure and the risk of infection at the population level. This includes homemade face masks, 
which are considered the last resort to prevent droplet transmission from the infected people, but it is better than if there is no protection at all [5]. The centers for disease control (CDC) [6] also stated that homemade cloth face masks (e.g., bananas and scarves) are advised as an alternative option in the limited resource circumstances.

This study developed a non-medical face mask made of local materials that can be effectively used to prevent disease transmission, i.e., the Go-Go ("godhong-gombal" [banana leaf-cloth]) mask. The uniqueness of this face mask is in the material used, which is the outworn household cloth with the addition of a banana leaf filter. The household cloth includes all types of usable outworn clothes or fabrics considered the primary material. The consideration in selecting these materials is that they should be affordable, easily obtainable, washable, or reusable. Some of the fabric materials that can be used include cotton shirts, headscarves, napkins, pillowcases, scarves, and bandanas [5], [7]. However, the ability of these materials to provide the filtration is still not optimal as the ideal mask should perform a filtration ability of at least $95 \%$ [5]. Therefore, the additional filter (in our study, it is a banana leaf) is needed to increase the filtration ability of the household cloth-based face mask.

The role of the leaves in this study is to filter water and microbes. If the face mask is made of household cloth, it is generally able to absorb water easily. The leaves' ability to be water-repellent or to not absorb much water is due to the banana leaves' structure that has a hydrophobic cuticle layer (composed of cutin and wax), small pores (stomata) 20-50 $\mu \mathrm{m}$, and deep leaf tissue (palisade, parenchyma) composed of filter-like pores [8], [9]. The structure make the leaves difficult to be penetrated by microorganisms [10]. Besides, banana leaves are natural materials that can be used immediately and are environmentally friendly since they are biodegradable. Another study using natural ingredients to improve the function of face masks is by adding root extract of liquorice (Glycyrrhiza glabra) which is an antimicrobial agent containing glycyrrhetinic acid (GA) and glycyrrhizin (GL) [11]. Research showed that this addition can increase the effectiveness of face masks in warding off microbes. However, studies on the use of natural materials to increase the effectiveness of mask filtration have not yet been found.

The selection of natural and reusable materials is also done to respond to the prolonged pandemic situation. The waste of personal protective equipment (PPE) from gloves, face (medical) masks, face shields, hazmat suits, and other equipment has sharply increased. If proper disposal is neglected, the increasing PPE and diagnostic tool waste can potentially cause new problems based on the environmental contamination potential [12]. According to the previous explanation, this study aimed to design a cloth face mask with the inserted banana leaf (biodegradable materials) and test its effectiveness.

\section{RESEARCH METHOD}

\subsection{Face mask design}

A series of face mask design trials were conducted based on the analysis of the needs and conditions in the field during pandemic. The innovation of the face mask design included three aspects: i) the cloth face masks which are easy to be produced or homemade cloth face masks (do-it-yourself, DIY face masks), ii) The pocket to insert the banana leaf filters, and iii) the additional layer specifically designed for the mouth covering. The developed mask pattern resulted from the adaptation and modification of the 3-dimensional (3D) mask pattern by Heeya [13].

The pattern selection was adjusted to the needs of the face mask development with the addition of a filter in the form of a leaf sheet. The 3D mask pattern has a flat section without any pleats. Therefore, it can be modified into a pocket to insert the leaf sheet. The size of the developed face mask pattern is still intended for adults consisting of pattern A (Figure 1(a)), pattern B (Figure 1(b)), pattern C (Figure 1(c)), pattern D (Figure 1(d)), and pattern E (Figure 1(e)). The production process can be accessed through https://youtu.be/d2OBVc00A2c.

\subsection{Effectivity test}

This study used two types of tests to measure the face mask effectivity:

\subsubsection{Bacterial filtration efficiency (BFE) test}

This test is used to measure how effective the face mask can filter out bacteria. We compared the cloth face masks with inserted leaf layers (Go-Go masks) and the cloth face masks without leaf layers. For the uncoated cloth test (without filter), different types of cloth materials were also compared. Bacterial filtration efficiency (BFE) test was performed using the total plate count method where the air cannot directly flow through the leaves. The test procedure included: i) the leaves were cleaned and wiped with a disinfectant (using hand rub) and were inserted in the masks, ii) the masks were set in the air blower to determine the mask ability to filter out bacteria, iii) the masks with the inserted layer of leaf were left untouched for four hours, iv) after four hours, the outer part of the mask was cut into a section of $2 \times 2 \mathrm{~cm}$ and jiggled into $50 \mathrm{ml}$ 
of sterile distilled water, v) having left idle for a while, and the bacteria count test was conducted in the distilled water, and vii) the test was continued with the fluids diluted for three times $(1: 1000)$ and rubbed on the media of agar. Finally, the bacterial count was observed.

Furthermore, the BFE test was conducted on various household fabrics used as mask material such as batik cloth, t-shirts, cotton, cotton ero, cotton, spun-bond, and polyester. Each type of fabric consists of three layers. However, specifically for spunbond and polyester, they are combined with cotton and each of which consists of one layer of cloth or fabric. For each type of cloth, five samples were used in this study. The test was conducted by the modified method of BFE. The test procedure included: i) Fastening the mask to the end of the pipe, ii) Creating the room airflow into the end of the pipe with the mask set, iii) Blocking the airflow out of the mask with the agar media, and d) Observing the bacteria count growing on the agar media.

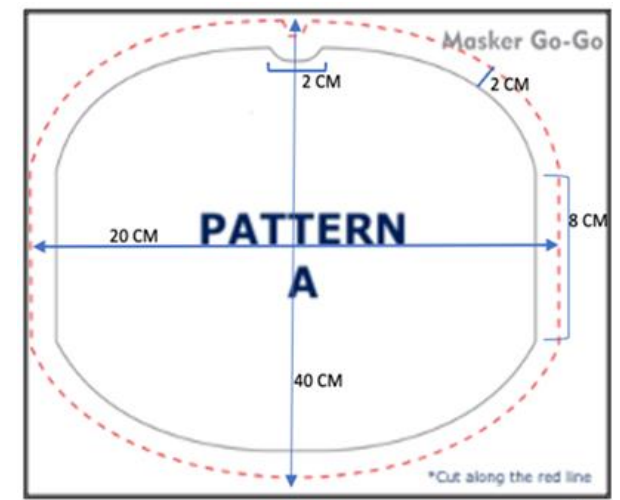

(a)

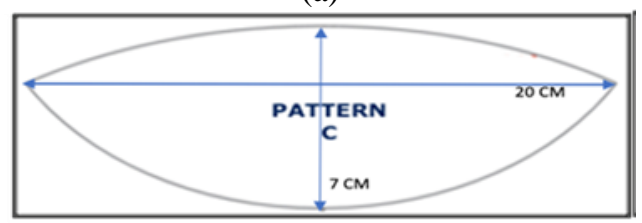

(c)

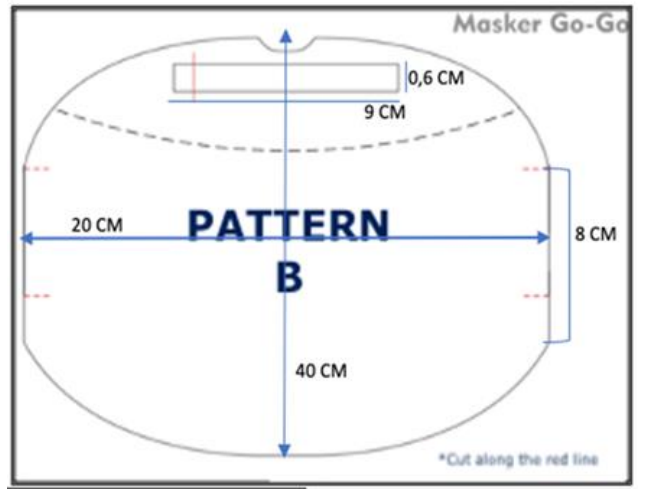

(b)

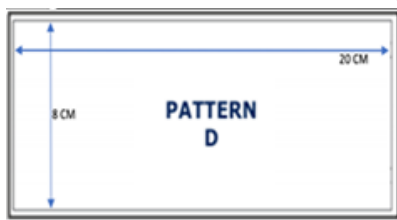

(d)

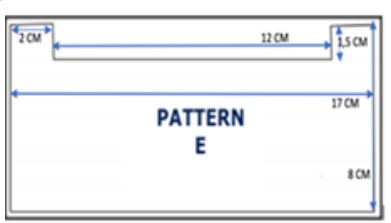

(e)

Figure 1. Pattern specifications: (a) Pattern A for cloth 1, (b) Pattern B for cloth 2, (c) Pattern C for the nose and chin section, (d) Pattern D for the pocket section, and (e) Pattern E for cloth 3, specifically designed for the mouth covering

\subsubsection{Water-resistant test}

The water-resistant test was conducted on three types of face masks, i.e., surgical masks, cloth masks, and banana leaf-filtered masks (Go-Go masks). The test was conducted by two methods, direct observation and the calculation of the weight gain of filter paper. The direct observation was made by analyzing whether the patches on the filter paper appeared inside the face mask. When the patches appeared on the filter paper, this indicated that fluids penetrated the face mask. The observations were made in three ways: the direct observation on visible patches (by eye), under UV-254 nm light, and UV-366 nm light.

The weight gain of filter paper was calculated based on the additional weight gain of filter paper after methylene blue fluids were sprayed on the mask's front part. This test was adapted from the American association of textile chemists and Colorist (AATCC) 42 water resistance test. The heavier filter paper showed that the fluids penetrated the mask and were absorbed in the filter paper. The more fluids detected in the filter paper, the greater potential for the mask to be penetrated by the fluids. The effectivity test result was statistically examined using the Chi-square test and Kruskal Wallis and then presented descriptively. This research has received approval from the Medical and Health Research Ethics Committee of the Faculty of Medicine, Public Health and Nursing (FKKMK) UGM with No. KE/FK/0831/EC/2020.

\section{RESULTS AND DISCUSSION}

\subsection{The design of the face masks}

The sewn face mask, based on the design development trials, results in a cloth mask sized $20 \times 18 \mathrm{~cm}$ with the details of eight $\mathrm{cm}$ in length on the front part and five $\mathrm{cm}$ on each part of the nose and chin 
(Figure 2). The face mask design pattern in this study refers to the requirements by the WHO [3], consisting of at least 3-4 layers of clothes depending on the type of material. It is in line with the study on the use of non-medical masks, suggesting that face masks should consist of several layers to improve filtration efficiency [14], [15]. The face mask designed in this study consists of the main (front) and the mask's additional (back) parts. The front part of the mask consisted of two layers of cloth, and the inside part consisted of one additional cloth layer specifically designed to cover the mouth. The additional specific cloth layer for the mouth covering was based on considering that the largest droplet volume and concentration are released as a person sneezes, coughs, and talks [16].

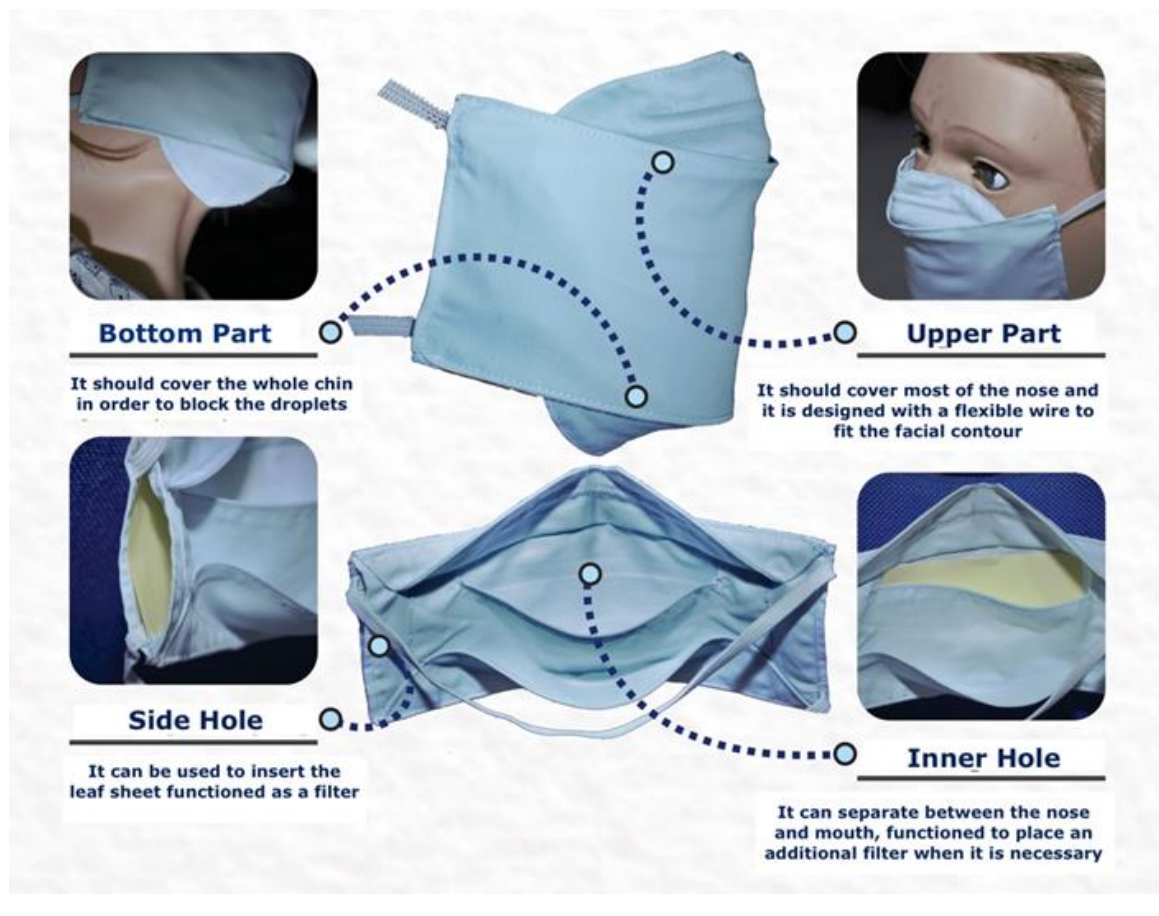

Figure 2. The application of the face mask design

The shape of the face masks can be designed as flat folded or resembling a duckbill [2], [17].Centers for Disease Control and Prevention (CDC) [6] provides an overview to independently produce masks (homemade cloth face masks) in flat folded form, including both seamless and non-seamless masks. Seamless masks can be produced by rolling a scarf or other materials into several folds. In addition, Davies et al. [17] described the guidance of mask production with a flat folded model. However, several designs of cloth face masks with some different shapes have also been developed. Dato et al. [18] developed a mask made of a flat layer made of T-shirts with some modifications, such as using three straps stitched together to the mask and the use of broader cloth. Meanwhile, Park and Jayaraman [19] redesigned the wider cloth face mask without pleats on the nose, chin, and ears to enhance convenience and protection.

Besides these options, other shapes of cloth face masks are found in the market, such as the semiduckbill design or known as the 3-dimensional (3D) masks, and in the basic shape called scuba or buff masks. The 3D mask model consists of a plain section without pleats on the front part and has a particular part covering the nose and chin. In comparison, the plain masks are designed without any special pleats and straps (the mask and straps are attached on the same cloth). However, scuba/buff masks are not recommended since these masks only consist of one layer of cloth and have loose pores [20].

The association française de normalization (AFNOR) requires that the size standard of cloth face mask should fit the facial morphology measured based on the anthropometry of bigonial width, the mentonsellion length, the inter pupillary distance, and bitregion chin curvature [21]. The mask pattern size is $20 \times 20 \mathrm{~cm}$ for the flat fold model and $21 \times 20 \mathrm{~cm}$ for the duckbill model. CDC [6] describes the mask pattern for a flat folded model with $25.4 \times 15.2 \mathrm{~cm}$, while Davies et al. [17] suggests the size of 20x16 cm in the same model. The size distinction of the mask pattern is caused by the differences in the facial morphology of each person based on race and ethnicity [22]. In this study, the size of the pattern used is based on the size of Korean adults who have racial similarities with Indonesians or Asians. 


\subsection{Bacterial filtration test}

The bacterial filtration test was conducted in two types of face masks: a mask with a layer of banana leaf (Go-Go mask) and a mask with the various types of fabrics.

\subsubsection{Bacterial filtration efficiency (BFE) test on masks with leaf layer}

The air could not directly feed the face masks with the leaf filtration. Therefore, a different test was applied, i.e., the total plate count method. The mask used for this test was made of cotton cloth with the inserted banana leaf filter inside. Table 1 shows that the outer part of the face mask using the leaf filter (A to D samples) contains significantly less bacteria than the face mask without the leaf filter (control).

Table 1. Bacterial filtration test on leaf-filtered face masks

\begin{tabular}{lc}
\hline \multicolumn{1}{c}{ Samples } & Bacterial population $\left(\mathrm{cfu} / \mathrm{cm}^{2}\right.$ cloth) \\
\hline Samples without leaf layer (control) & $30 \times 10^{3}$ \\
Samples with leaf layer A & Not detected \\
Samples with leaf layer B & $0.25 \times 10^{3}$ \\
Samples with leaf layer C & $0.50 \times 10^{3}$ \\
Samples with leaf layer D & $0.50 \times 10^{3}$ \\
\hline
\end{tabular}

The primary function of the face mask is filtering and preventing the entry of disease-causing microorganisms or other pollutants. The filtration mechanism consists of a combination of interception, diffusion, impaction (inertial impaction), and electrostatic filtration [22], [23]. Inertial impaction and interception are the mechanisms responsible for collecting larger particles $(>5 \mu \mathrm{m})$, while diffusion is responsible for collecting smaller particles. Some filters made of charged fibers have an electrostatic filtration mechanism to collect larger and smaller particles. This mechanism is essential to ensure that medical protective equipment meets the filtration efficiency standards issued by the national institute for occupational safety and health (NIOSH). It will increase the particle collection without interfering with the respiratory process [24].

The filtration efficiency of the face mask must be supported by a layer of material that provides those four abilities. Previous studies have shown that cloth facemasks had the ability to reduce particulate exposure and thus provide some level of protection to the wearer [15], [25]. Various materials have been developed to enhance the mask's filtration function. This study identifies the banana leaf as an additional filter for cloth face masks. The filtration mechanism of the leaves is related to the ability of the leaves for self-cleaning. The mechanism of self-cleaning on banana leaves as a hydrophobic plant occurs through three critical processes, i.e., rough surfaces, reduction of particle adhesion, and fluid resistance [26]. In addition to the structure of the leaves that make them hardly penetrated by water, the mechanism of self-cleaning also allows the particles to not adhere much.

The result of the BFE test showed that banana-leaf filtered cloth face masks had a better average bacterial filtration ability than the masks without the leaf filter as shown in Table 1. It is due to the structure of the leaves that is hardly penetrated by microorganisms. Basically, a leaf provides a habitat ecosystem for various microorganisms called the "phyllosphere" [27]. Various microbes, both pathogens, and saprophytes can survive and even multiply on the leaf surface. Pathogens must cross the surface of the cuticle to gain access to the intercellular spaces and inner tissues of the leaf. Some fungal pathogens can directly penetrate the epidermis using cuticle- and cell wall-destroying enzymes, mechanical forces, or both [28]. However, bacteria cannot directly penetrate the epidermis and enter the leaf tissue by an alternative mechanism through natural openings on the surface such as stomata and hydathodes (the pores on the leaf edge).

The abundant number of stomata on the surface of banana leaf is one of the most important routes for the entry of pathogenic bacteria [29]. The size of stomata depends on the types of banana plants in Indonesia: the type of "Penjalin" (Musa acuminata) $(26.488 \pm 1.288 \mu \mathrm{m})$, "Kluthuk warangan" (Musa balbisiana) (26.488 $\pm 2.962 \mu \mathrm{m})$, “Warangan Ambon” (Musa acuminata) (33.572 $\pm 2.284 \mu \mathrm{m})$, "Kluthuk susu” (Musa paradisiaca) (33.418 $\pm 0.689 \mu \mathrm{m})$, and "Raja Nangka” (Musa acuminata x Musa balbisiana) $(32.956 \pm 2.066 \mu \mathrm{m})$ [30]. The large size of the stomata allows the bacteria with an average size of 0.6 to 0.8 $\mu \mathrm{m}$ to penetrate the leaf surface. The length of the banana plant stomata will also change if it is in a fruitful state. The more aged the fruit is, the wider the stomata size [31]. Therefore, the ideal banana leaf that is inserted is from the banana plant, which does not bear the fruits. The wounds or the damage on the leaf surface caused by insects or environmental, mechanical damage, such as rain and wind, can be the potential routes of bacteria to enter the leaves in addition to the natural openings [32]. Therefore, selecting the whole, undamaged leaves as filters on the cloth face masks is highly recommended. 


\subsubsection{Bacterial filtration efficiency (BFE) test on the clothes without leaf layer}

The bacterial filtration test was conducted on various types of household clothes commonly used as the face mask-making material shows in Table 2. All types of clothes can filter bacteria and the best filtration results are from the combined clothes (cotton, polyester, and spunbond).

Table 2. Bacterial filtration on different types of clothes

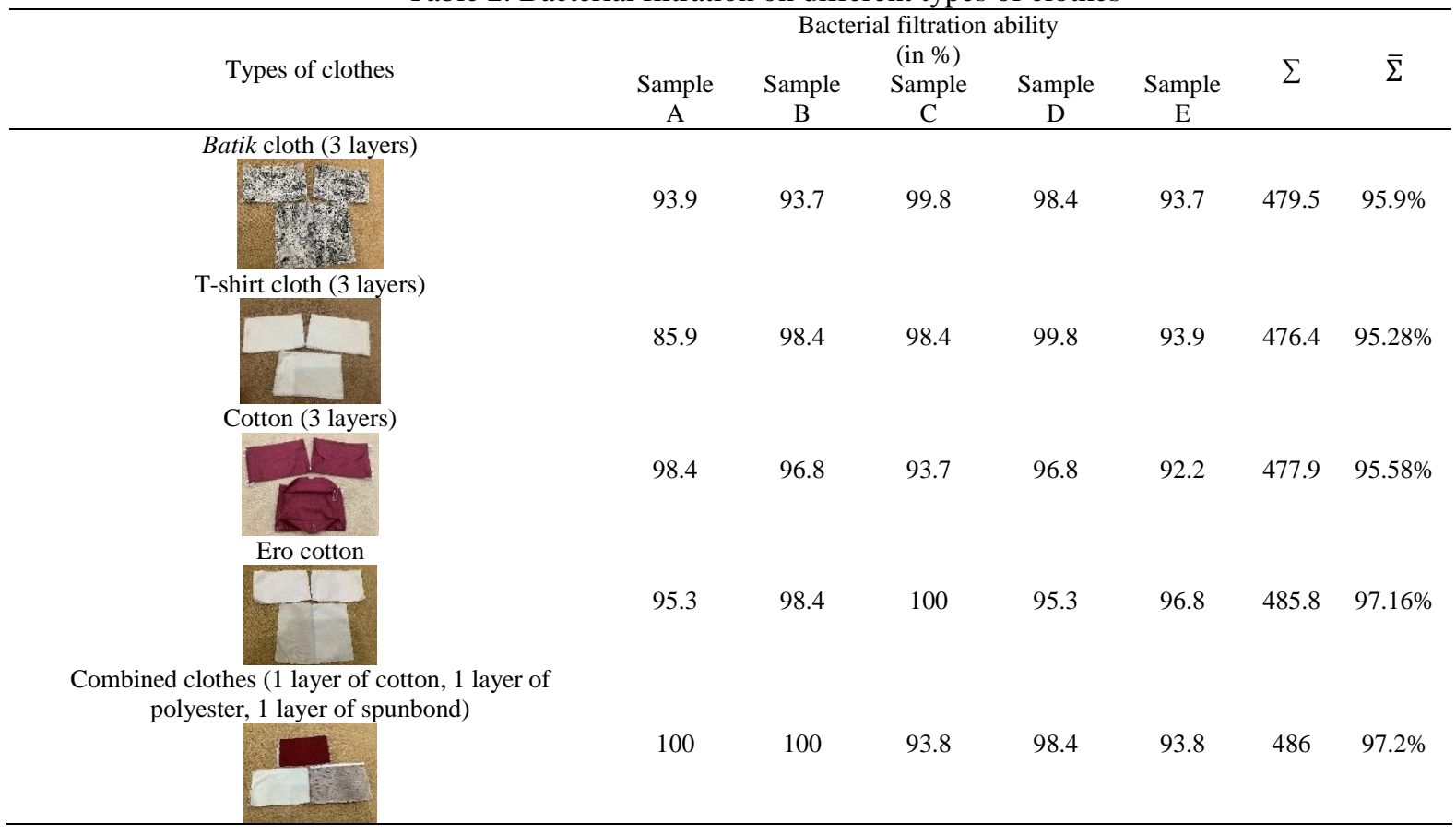

As previously mentioned, one of the bases of this study is using the most available materials of household cloth. However, the data showing the type of cloth widely used by the people to produce masks are not yet identified. Based on the survey conducted by the authors on 98 respondents, only $30.3 \%$ said that they wanted to produce their cloth masks of household fabrics. Considering these responses, the cloth chosen as mask materials for this study was the most widely used household cloth. Based on the survey conducted by the authors, the most widely used mask materials were cotton, t-shirts, batik cloth, and ero cotton (unpublished data). The selected cloth was then used to develop 3-layer cloth masks.

Table 2 shows that all fabrics have a bacterial filtration efficiency of more than $90 \%$. Based on ASTM standards, surgical masks have a bacterial filtration ability of at least 95\% (ASTM level 3) and 98\% (ASTM level 2 and 1) [33]. In line, a study found that single-layer of homemade masks did not met the standard of BFE. In contrast, three double-layer materials can met the BFE standard [34]. Additionally, a systematic review of published studies found that cloth mask efficiency is higher when made of multiple layers [35].

Bacterial filtration studies showed that surgical masks have an average bacterial filtration ability of 96.35\% (from Bacillus atrophaeus) and $89.52 \%$ (from bacteria bacteriophage MS2). Bacillus atrophaeus and bacteriophage MS2 are $0.95-1.25 \mu \mathrm{m}$ and $23 \mathrm{~nm}$ in diameter, respectively [5]. In this study, the types of tested bacteria were any bacteria remaining in the air. There were no assessments on the types of bacteria present in the air and the types of bacteria growing on the agar media.

Davies et al. [5] showed that household fabrics, such as napkins and cotton shirts, provide a less than $90 \%$ filtration ability. Supposing the face mask is arranged in two layers of the same cloth material, in that case, it significantly increases the bacterial filtration ability, although it cannot match the bacterial filtration ability of surgical masks [5], [36]. However, if the cloth layer comprises three layers, the bacteria filtration ability is almost similar to surgical masks' filtration ability [2]. In this study (Table 2), all the types of fabrics tested were composed of three layers with average bacteria filtration ability as following: cotton (95.58\%), t-shirt cloth (95.28\%), batik cloth (95.9\%), and ero cotton $(97.16 \%)$.

This study also tested the bacterial filtration ability of face masks with three different fabric layers based on the WHO recommendations, i.e., the hydrophobic material for the outer part, the cloth layer with the maximum filtration ability for the middle part, and hydrophilic cloth material for the inner part [3]. The 
fabrics used in this study were spunbond for the outer part, polyester for the second or the middle layer, and cotton for the third or the inner layer. The result of this bacterial filtration test showed a filtration ability of 97.2\% (Table 3). Each type of fabric has its characteristic in determining the bacterial filtration ability. This is mainly determined by the pore size and the density of the fabric [37]. Fabrics with loose pores such as gauze or fabrics with tight pore structures are not recommended to be the mask material [3]. The bacterial filtration ability of masks is related to the mask's ability to prevent disease transmission. The better the ability of the cloth to filter bacteria, the lower the risk of infection for the wearers [38].

Table 3. Differences of water resistant potency based on the patches visibility

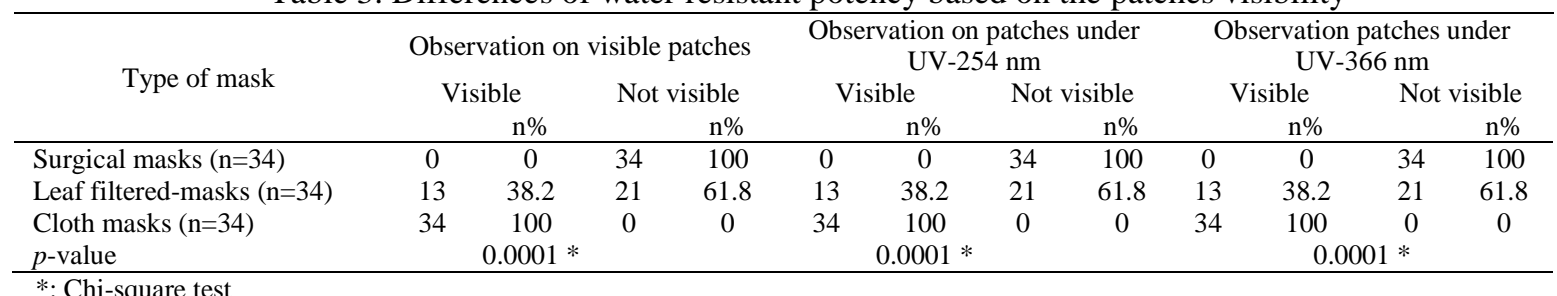

*: Chi-square test

\subsection{Water resistant test}

The water-resistant test was conducted on three types of face masks (surgical masks, cloth masks, and leaf-filtered masks) based on the results of direct observation and the calculation of the weight gain of filter paper.

\subsubsection{Direct observation}

Observing the visible patches, observing the patches under UV-254 nm light and UV-366 nm light, and direct observations were made. Based on Table 3, surgical masks are the best masks out of the three types of masks in retaining fluids in all three observations since none of these masks $(0 \%)$ were penetrated by the fluids. Furthermore, there were only $13(38.2 \%)$ leaf-filtered masks that were penetrated by the fluids. In contrast, the fluids penetrated all cloth masks. Further analysis indicated that the difference in the ability of water-resistance of the three masks was significant ( $p$-value $<0.0001)$.

\subsubsection{Calculation of the weight gain of filter paper}

The assessment of water resistance was observed from the additional weight of the filter paper after spraying the fluids on the front part of the mask. Based on the mean rank value, the highest weight gain of filter paper was found in the cloth masks (83.50), and then leaf-filtered masks (44.00), and finally surgical masks (27.00). The difference in weight gain was statistically significant (p-value<0.0001). Table 4 shows the calculations of weight gain of each filter paper.

Table 4. The difference of weight gain of filter paper on face masks

\begin{tabular}{lcccc}
\hline \multicolumn{1}{c}{ Mask type } & Mean $(\mathrm{g})$ & Median $(\mathrm{g})$ & Mean rank & p-value \\
\hline Surgical masks $(\mathrm{n}=34)$ & 0 & 0.0 & 27.0 & \\
Leaf-filter mask $(\mathrm{n}=34)$ & 0.42 & 0.0 & 44.0 & $0.0001 *$ \\
Cloth mask $(\mathrm{n}=34)$ & 0.3 & 0.3 & 83.5 & \\
\hline
\end{tabular}

*: Kruskal Wallis

The ability of face masks to retain the fluids is essential to provide effective protective function and filtration ability. Surgical masks and disposable respirators must be designed to be fluid-resistant [24]. Meanwhile, cloth face masks are not standardized to have this ability [6], [21]. However, several ways may improve the water-resistance ability of cloth face masks, such as layered fabrics and the modification of a particular material. In this study, masks were developed by modifying the available local materials, particularly in limited resources circumstances. We used layered cotton cloth and the inserted banana leaf sheet as an additional filter to increase the ability of the masks to retain the fluids.

Banana leaves have the hydrophobic ability of retaining fluids and are self-cleaning. This ability is called the banana leaf effect (BLE) [8]. The hydrophobic character of the leaves is due to the presence of convex epidermal cells, rough leaf surfaces, and dense epicular wax [26]. The wax can be dissolved under temperature of $100^{\circ} \mathrm{C}\left(90^{\circ} \mathrm{C}\right)$. When the wax is dissolved, its hydrophobic nature decreases due to reduced 
adhesion force. The adhesion force is the ability of the leaves to retain fluids that adhere to their surface. A study showed that the higher the heating temperature and the pressure, the lower the adhesion force [39]. Therefore, the banana leaf used for the mask filtration is not required to be heated through a particular mechanism, and wilting it at room temperature is sufficient.

The result obtained from the direct observation and the calculation of the weight gain of filter paper showed that although leaf-filtered masks do not provide equal water resistance ability as compared to surgical masks, the leaf filtered masks have better ability than the cloth masks without leaf filter. The leaf function that is not optimal in retaining water can be possibly caused by technical factors, for example, if the leaf sheet does not cover the entire part of the mask. Furthermore, some significant findings should be considered to optimize the use of leaves as additional filtration in face masks, such as selecting the leaf type and the mask design. The too young leaf is not readily inserted into the mask pocket because it is too soft, easily withers, and tends to curl. Every banana leaf grows from the middle pseudostem in the form of cylindrical rolls (cigar leaf) [40]. Young banana leaves will be tightly circular, whitish, and very brittle [41]. The shape of the banana leaf varies based on age, gradually changing from a tightly rolled vertical cylindrical shape to a widened horizontal posture [42]. Therefore, selecting completely expanded leaves is highly recommended for mask filters.

In addition, the face mask design is essential to optimize the modification of the banana leaf sheet and the cloth in retaining the fluids. A mask that has multiple stitches will allow fluids to penetrate more easily through the suture holes. AFNOR [21] mentioned that a good mask should have tight stitches and fewer creases among the stitches to avoid the air (small particles) leaking through the seams. Additionally, it is not recommended to stitch vertically in the middle of the mask above the mouth and under the nose. The face mask developed in this study is a plain-designed face mask without stitching on the front part. Based on the stitched face mask design recommended by the AFNOR, CDC, and the WHO, all stitches are on the edge of the mask to reduce the leaking.

\section{CONCLUSION}

The Go-Go leaf-filtered cloth face mask design is made with the dimensions of $20 \times 18 \mathrm{~cm}$, with the model of a semi-duckbill design consisting of three layers of cotton cloth equipped with a pocket to insert a banana leaf sheet. The mask effectivity measured by two mask effectivity standards (bacterial filtration and water resistance) shows that the leaf-filtered mask made of three layers of cloth is more effective in filtering bacteria and retaining fluids than a mask made of only one cloth. However, further studies are required to identify the effectiveness of the face mask combination based on the breathability aspect.

\section{ACKNOWLEDGEMENTS}

This study was financially supported by Dana Masyarakat Grant, Faculty of Medicine, Public Health and Nursing, Universitas Gadjah Mada (2020). The authors thank Endah Ratnasari for the critical reading of this manuscript.

\section{REFERENCES}

[1] Zhou Wang, Wang Qiang, and Hu, "A Handbook of 2019-nCoV Pneumonia Control and Prevention," Hubei Science and technology press, pp. 1-108, 2020.

[2] WHO, "Mask use in the context of COVID-19: Interim guidance," World Health Organization, 2020. https://www.who.int/publications/i/item/advice-on-the-use-of-masks-in-the-community-during-home-care-and-in-healthcaresettings-in-the-context-of-the-novel-coronavirus-(2019-ncov)-outbreak (accessed May 25, 2021).

[3] WHO, "Advice on the use of masks in the context of COVID-19: Interim guidance," World Health Organization, 2020. https://apps.who.int/iris/handle/10665/331693 (accessed May 25, 2021).

[4] M. van der Sande, P. Teunis, and R. Sabel, "Professional and home-made face masks reduce exposure to respiratory infections among the general population," PLOS ONE, vol. 3, no. 7, p. e2618, Jul. 2008, doi: 10.1371/journal.pone.0002618.

[5] A. Davies, K. A. Thompson, K. Giri, G. Kafatos, J. Walker, and A. Bennett, "Testing the efficacy of homemade masks: would they protect in an influenza pandemic?," Disaster medicine and public health preparedness, vol. 7, no. 4, pp. 413-418, Aug. 2013, doi: 10.1017/dmp.2013.43.

[6] CDC, "How to Select, Wear, and Clean Your Mask," Cdc, 2020. https://www.cdc.gov/coronavirus/2019-ncov/prevent-gettingsick/about-face-coverings.html (accessed Oct. 13, 2021).

[7] W. Mueller et al., "The effectiveness of respiratory protection worn by communities to protect from volcanic ash inhalation. Part I: Filtration efficiency tests," International Journal of Hygiene and Environmental Health, vol. 221, no. 6, pp. 967-976, Jul. 2018, doi: 10.1016/j.ijheh.2018.03.012.

[8] H. A. Hassan, M. J. Ghazali, C. H. Azhari, and C. Meric, "Microstructural effects of banana leaf on adhesion and self cleaning behaviour," MATEC Web of Conferences, vol. 87, no. 3, p. 02026, Dec. 2016, doi: 10.1051/matecconf/20178702026.

[9] V. Suseela, "Potential roles of plant biochemistry in mediating ecosystem responses to warming and drought," in Ecosystem Consequences of Soil Warming, Elsevier, 2019, pp. 103-124.

[10] W. Aragón, J. J. Reina-Pinto, and M. Serrano, "The intimate talk between plants and microorganisms at the leaf surface," Journal of experimental botany, vol. 68, no. 19, pp. 5339-5350, Nov. 2017, doi: 10.1093/jxb/erx327. 
[11] M. A. Chowdhury et al., "Prospect of biobased antiviral face mask to limit the coronavirus outbreak," Environmental Research, vol. 192, no. November, p. 110294, Jan. 2021, doi: 10.1016/j.envres.2020.110294.

[12] J. J. Klemeš, Y. Van Fan, and P. Jiang, "The energy and environmental footprints of COVID-19 fighting measures - PPE, disinfection, supply chains," Energy, vol. 211, p. 118701, Nov. 2020, doi: 10.1016/j.energy.2020.118701.

[13] Heeya, "Heeya's Small Workshop -Naver Blog," 2020.//blog.naver.com/autoyou11/221821193913 (accessed May 25, 2021).

[14] A. Konda, A. Prakash, G. A. Moss, M. Schmoldt, G. D. Grant, and S. Guha, "Aerosol Filtration Efficiency of Common Fabrics Used in Respiratory Cloth Masks," ACS Nano, vol. 14, no. 5, pp. 6339-6347, May 2020, doi: 10.1021/acsnano.0c03252.

[15] E. O'Kelly, S. Pirog, J. Ward, and P. J. Clarkson, “Ability of fabric face mask materials to filter ultrafine particles at coughing velocity,” BMJ open, vol. 10, no. 9, p. e039424, Sep. 2020, doi: 10.1136/bmjopen-2020-039424.

[16] J. Schijven, L. C. Vermeulen, A. Swart, A. Meijer, E. Duizer, and A. M. de Roda Husman, "Quantitative microbial risk assessment for airborne transmission of sars-cov-2 via breathing, speaking, singing, coughing, and sneezing," Environmental Health Perspectives, vol. 129, no. 4, p. 047002, Apr. 2021, doi: 10.1289/EHP7886.

[17] A. Davies, K.-A. Thompson, K. Giri, G. Kafatos, J. Walker, and A. Bennett, "Facemask instructions with template Covid-19," 2020. https://www.researchgate.net/publication/340280191_Facemask_instructions_with_template_Covid-19 (accessed May 25, 2021).

[18] V. M. Dato, D. Hostler, and M. E. Hahn, "Simple respiratory mask," Emerging Infectious Diseases, vol. 12, no. 6, pp. 1033-1034, Jun. 2006, doi: 10.3201/eid1206.051468.

[19] S. Park and S. Jayaraman, "From containment to harm reduction from SARS-CoV-2: a fabric mask for enhanced effectiveness, comfort, and compliance," Journal of the Textile Institute, vol. 112, no. 7, pp. 1144-1158, Jul. 2021, doi: 10.1080/00405000.2020.1805971

[20] Indonesian Ministry of Health , "The Ministry of Health Suggests 3 Types of Masks to Wear (In Indonesia: Kemenkes Sarankan 3 Jenis Masker untuk Dipakai)," Kementerian Kesehatan RI, 2020.https://www.kemkes.go.id/article/view/20092200001/kemenkessarankan-3-jenis-masker-untuk-dipakai.html (accessed May 25, 2021).

[21] AFNOR, "Barrier mask-serial manufacture and artisanal making (or DIY) (Afnor Spec S76-001)," 2020. https://api.pks.rs/storage/assets/AFNOR-SPEC-S76-001-Barrier-masks-27032020.pdf (accessed May 25, 2021).

[22] L. Yang, R. Wei, and H. Shen, "The fractal characteristic of facial anthropometric data for developing PCA fit test panels for youth born in central China," Journal of Occupational and Environmental Hygiene, vol. 14, no. 1, pp. 9-16, Jan. 2017, doi: 10.1080/15459624.2016.1207778.

[23] J. F. Robinson, I. Rios de Anda, F. J. Moore, J. P. Reid, R. P. Sear, and C. P. Royall, "Efficacy of face coverings in reducing transmission of COVID-19: calculations based on models of droplet capture," Physics of Fluids, vol. 33, no. 4, p. 043112, Apr. 2021, doi: $10.1063 / 5.0047622$.

[24] C. Gordon and A. Thompson, "Use of personal protective equipment during the COVID-19 pandemic," British Journal of Nursing, vol. 29, no. 13, pp. 748-752, Jul. 2020, doi: 10.12968/bjon.2020.29.13.748.

[25] K. M. Shakya, A. Noyes, R. Kallin, and R. E. Peltier, "Evaluating the efficacy of cloth facemasks in reducing particulate matter exposure," Journal of Exposure Science and Environmental Epidemiology, vol. 27, no. 3, pp. 352-357, May 2017, doi: 10.1038/jes.2016.42.

[26] W. Barthlott and C. Neinhuis, "Purity of the sacred lotus, or escape from contamination in biological surfaces," Planta, vol. 202, no. 1, pp. 1-8, Apr. 1997, doi: 10.1007/s004250050096.

[27] S. S. Hirano and C. D. Upper, "Bacteria in the Leaf Ecosystem with Emphasis on Pseudomonas syringae —a Pathogen, Ice Nucleus, and Epiphyte," Microbiology and Molecular Biology Reviews, vol. 64, no. 3, pp. 624-653, Sep. 2000, doi: 10.1128/MMBR.64.3.624-653.2000.

[28] G. Doehlemann, B. Ökmen, W. Zhu, and A. Sharon, "Plant pathogenic fungi," Microbiology Spectrum, vol. 5, no. 1, Jan. 2017, doi: 10.1128/microbiolspec.funk-0023-2016.

[29] M. Melotto, L. Zhang, P. R. Oblessuc, and S. Y. He, "Stomatal defense a decade later," Plant Physiology, vol. 174, no. 2, pp. 561-571, Jun. 2017, doi: 10.1104/pp.16.01853.

[30] I. Sumardi and M. Wulandari, "Anatomy and morphology character of five Indonesian banana cultivars (Musa spp.) of different ploidy level," Biodiversitas Journal of Biological Diversity, vol. 11, no. 4, pp. 167-175, Oct. 2010, doi: 10.13057/biodiv/d110401.

[31] C. Santhakumari and K. V. Krishnamurthy, "Development of epidermis on banana fruits," Biologia Plantarum, vol. 33, no. 4, pp. 325-331, Jul. 1991, doi: 10.1007/BF02885381.

[32] J. Kumar, A. Ramlal, K. Kumar, A. Rani, and V. Mishra, "Signaling pathways and downstream effectors of host innate immunity in plants," International Journal of Molecular Sciences, vol. 22, no. 16, p. 9022, Aug. 2021, doi: 10.3390/ijms 22169022.

[33] M. H. Chua et al., "Face masks in the new COVID-19 normal: materials, testing, and perspectives," Research, vol. 2020, pp. 140, Aug. 2020, doi: 10.34133/2020/7286735.

[34] D. Wang et al., "Selection of homemade mask materials for preventing transmission of COVID-19: A laboratory study," PLoS ONE, vol. 15, no. 10 October, p. e0240285, Oct. 2020, doi: 10.1371/journal.pone.0240285.

[35] M. Santos et al., "Are cloth masks a substitute to medical masks in reducing transmission and contamination? A systematic review," Brazilian Oral Research, vol. 34, pp. 1-17, 2020, doi: 10.1590/1807-3107bor-2020.vol34.0123.

[36] W. C. Hill, M. S. Hull, and R. I. MacCuspie, "Testing of commercial masks and respirators and cotton mask insert materials using SARS-CoV-2 Virion-sized particulates: comparison of ideal aerosol filtration efficiency versus fitted filtration efficiency," Nano Letters, vol. 20, no. 10, pp. 7642-7647, Oct. 2020, doi: 10.1021/acs.nanolett.0c03182.

[37] K. P. Lee, J. Yip, C. W. Kan, J. C. Chiou, and K. F. Yung, "Reusable face masks as alternative for disposable medical masks: Factors that affect their wear-comfort," International Journal of Environmental Research and Public Health, vol. 17, no. 18, pp. 1-16, Sep. 2020, doi: 10.3390/ijerph17186623.

[38] A. M. Wilson et al., "COVID-19 and use of non-traditional masks: how do various materials compare in reducing the risk of infection for mask wearers?," Journal of Hospital Infection, vol. 105, no. 4, pp. 640-642, Aug. 2020, doi: 10.1016/j.jhin.2020.05.036.

[39] M. J. Ghazali, H. A. Hassan, C. H. Azhari, and F. A. Mamat, "The bio-adhesion behaviour of banana leaves as soil remover at elevated temperatures," Tribology Online, vol. 11, no. 2, pp. 264-271, 2016, doi: 10.2474/trol.11.264.

[40] A. Pereira and M. Maraschin, "Banana (Musa spp) from peel to pulp: Ethnopharmacology, source of bioactive compounds and its relevance for human health,” Journal of Ethnopharmacology, vol. 160, pp. 149-163, Feb. 2015, doi: 10.1016/j.jep.2014.11.008.

[41] Anne Vézina, "Musa paradisiaca," ProMusa, 2019. https://www.promusa.org/Musa+paradisiaca (accessed May 25, 2021).

[42] D. Karamura, E. Karamura, and G. Blomme, "General Plant Morphology of Musa," in Banana Breeding, no. January, CRC Press, 2011, pp. 1-20. 


\section{BIOGRAPHIES OF AUTHORS}
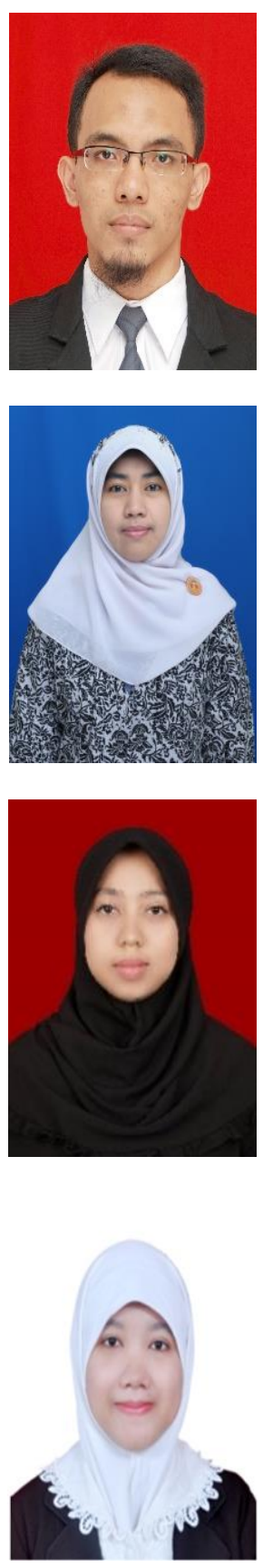

Mohamad Saifudin Hakim (iD BD SC P started his medical school at the Faculty of Medicine, Universitas Gadjah Mada, Yogyakarta Indonesia (2003-2007). After two years of clinical internship (2007-2009), he obtained his medical degree (MD) in 2009. He obtained his master degree in the Research Master Program of Infection and Immunity, Erasmus Medical Center (EMC) Rotterdam, the Netherlands (2011-2013). He then obtained his $\mathrm{PhD}$ degree at the Postgraduate School of Molecular Medicine, Erasmus Medical Center (EMC) Rotterdam. His $\mathrm{PhD}$ research focus on virus-drug-host interactions, especially hepatitis virus and rotavirus. Currently, he is an academic staff at the Department of Microbiology, Faculty of Medicine, Public Health and Nursing, Universitas Gadjah Mada Yogyakarta Indonesia. He can be contacted at email: m.s.hakim@ugm.ac.id.

Mumtihana Muchlis (D) SI SC P is a midwife and lecturer in Vocational College of Universitas Gadjah Mada, Yogyakarta. She received a Bachelor's degree in Polytechnic of Health, Ministry of Health, Yogyakarta and a Master degree in Universitas Sebelas Maret. Her research focus on women reproductive, health education, and health science. She can be contacted at email: mumtihana@ugm.ac.id.

Fitra Duhita (D) 8 SC $P$ is a midwife and midwifery lecturer with research interested in midwifery care, health professional education, and health science. She was a lecturer in the midwifery program at Vocational College, Universitas Gadjah Mada Yogyakarta until 2020. She is recently as a midwifery lecturer in Polytechnic of Health, Ministry of Health, Sorong, West Papua. She can be contacted at email: fitra.duhita@ugm.ac.id.

Rita Dian Pratiwi (D) 81 SC P is lecturer in Vocational College of Universitas Gadjah Mada, Yogyakarta. Her research interest is health information management, infectious diseases especially tuberculosis and epidemiology. She is an editor in the chief Jurnal Kesehatan Vokasional since 2016 until now. She can be contacted at email: ritadianp@ugm.ac.id. 